\title{
PATOLOGIZAÇÃO DA TRANSEXUALIDADE SOB A ÓTICA JURÍDICA: MAL (DES)NECESSÁRIO
}

\author{
Welington Oliveira de Souza dos Anjos Costa ${ }^{1}$ \\ Livia Gaigher Bósio Campello²
}

\begin{abstract}
RESUMO: Este artigo trata da patologização da transexualidade, fato cuja problemática tem sido ignorada para viabilizar a realização do tratamento transgenitalizador pelos meios públicos. A pesquisa objetiva definir a transexualidade para, em seguida, apontar o problema de sua incursão como patologia e, ao mesmo tempo, a solução desta inclusão patológica no auxílio da realização da cirurgia de redesignação sexual pelo Sistema Único de Saúde - SUS. Aponta-se a ofensa direta à dignidade da população trans e os supostos benefícios decorrentes da situação posta. O trabalho, bibliográfico e documental, desenvolve-se a partir dos métodos indutivo e dedutivo.
\end{abstract}

PALAVRAS-CHAVE: Transexualidade e Direito; Transexualidade e Disforia de Gênero; Dignidade da Pessoa Humana nas Questões Jurídicas de Gênero e Sexualidade.

\section{PATHOLOGIZATION OF TRANSEXUALITY UNDER THE JURIDICAL VISION: (UN)NECESSARY BAD}

\begin{abstract}
This article deals with the pathologization of transsexuality, a fact whose problematic has been ignored to make the public transgender treatment possible. The research aims to define transsexuality to then point out the problem of its incursion as pathology and, at the same time, the solution of this pathological inclusion in the aid of the realization of the sexual reassignment surgery by the Unified Health System. The paper shows the direct offense to the dignity of the trans population and the suposed benefits arising from the situation. The work, bibliographical and documental, is developed from the inductive and deductive methods.
\end{abstract}

KEYWORDS: Law and Transsexuality; Gender Identity Disorder; Human Being Dignity in Legal Matters of Gender and Sexuality.

\footnotetext{
${ }^{1}$ Mestre em Direito pela Universidade Federal de Mato Grosso do Sul e Doutorando em Direito pela Universidade de São Paulo e Universidade Federal de Mato Grosso do Sul. Membro da Diretoria Executiva da Federação Nacional dos Pós-Graduandos em Direito - FEPODI. Pesquisa Identidades e Questões de Gênero na Área Jurídica. E-mail: Well.eu@bol.com.br.

${ }^{2}$ Pós-Doutorado em Direito do Estado pela Universidade de São Paulo - USP, Doutorado em Direito das Relações Econômicas e Internacionais pela Pontifícia Universidade Católica de São Paulo - PUC/SP e Mestrado em Políticas Públicas e Processo pelo Centro Universitário Fluminense - UNIFLU. Professora adjunta da Faculdade de Direito na Universidade Federal de Mato Grosso do Sul (UFMS). E-mail: liviagaigher@ gmail.com.
} 


\section{INTRODUÇÃO}

A causa LGBT (Gays, Lésbicas, Bissexuais, Transexuais Travestis e Transgêneros) é extensa e dinâmica. Sua luta é diária e muitas vezes silenciada por diversas formas de imposição de identidade heterossexual nas práticas sociais mais variadas, inclusive na saúde. Nesse sentido, a discussão despontada neste trabalho refere-se à necessidade da despatologização da transexualidade, cuja patologização vem servindo como motivo para práticas de preconceito e exclusão social desta parcela social. Inclusive, a pesquisa em questão é uma vertente da campanha espanhola denominada Stop Trans Pathologization (STP, 2012), traduzida como "Parem a Patologização Trans", tão difundida por em sede internacional e atualmente nacional.

Isto porque, malgrado todas as nuances relativas à sexualidade, especialmente a formação da identidade de gênero, a transexualidade ainda consta inserida no código internacional de doenças psíquicas como transexualismo, ou seja, identidade associada à doença, assim como se encontra incluída no Manual de Diagnóstico Estatístico de Transtornos Mentais - DSM-4 como sendo disforia de gênero.

E dito diagnóstico psiquiátrico, logo patológico, da transexualidade tem subsidiado o tratamento gratuito pelo Sistema Único de Saúde - SUS que culmina na realização da cirurgia de redesignação sexual e, portanto, acaba servindo como subterfúgio por parte da própria comunidade trans (aqui entendida apenas como transexuais), a qual, envolvida em um discurso heteronormativo de dominação, acata as formas de enquadramento social impostas e, consequentemente, endossa a problemática aqui discutida.

Por outro lado, é necessária conscientização dos efeitos desta prática, implementandose a luta a fim de que não seja necessário diagnóstico para, somente então, realizar-se a cirurgia de redesignação sexual, mas o pleno atendimento em consideração à identidade de gênero, esta não associada a problemas mentais, preservando-se principalmente a dignidade das pessoas transexuais.

Por essa razão a proteção jurídica demonstra-se salutar na preservação da identidade da população transexual, levando-se muito mais em conta a sua dignidade e direito constitucional à intimidade do que sua genital, estando esta adequada ou não ao que se espera e entenda como "normal" pela sociedade heteronormativa.

Portanto, a pesquisa ora posta, que na verdade deve mais ser considerada um breve ensaio, ante a profundidade do tema, divide-se em quatro momentos: primeiro a conceituação da transexualidade para, em seguida, inseri-la na problemática da necessidade de sua 
patologização para garantia do atendimento público gratuito. Após, discute-se a necessária correlação da situação com o direito e, por fim, apresenta-se nova perspectiva para o tratamento com a causa trans em termos de atendimento junto ao SUS em Políticas Públicas, apontandose a necessidade de modificação do olhar para a busca da igualdade sem que para isso seja necessário submeter-se a laudo médico psiquiátrico.

Como critérios de inclusão, aqui tratamos de pessoas transexuais, na forma explicitada logo no início da abordagem da pesquisa. Também é imperioso frisar que o artigo não é construído sob a ótica de pessoas trans, mas pretende aprofundar a pesquisa na temática, que urge ser inserida nas discussões jurídicas atuais, tendo como marco teórico os estudos de gênero e desenvolvida de forma bibliográfica e documental, a partir dos métodos indutivo e dedutivo.

\section{CONCEITOS DE TRANSEXUALIDADE}

Transexual, em visão simples e essencialista, será a pessoa que sente de forma irreversível desejo de pertencer ao sexo contrário ao que lhe foi genética e morfologicamente estabelecido (PERES \& TOLEDO, 2011, p. 448). Em visão mais balizada e atual, por outro lado, transexualidade é uma forma identitária que difere do gênero constante em seus registros públicos em razão destes não retratarem a sua vivência de gênero, que é uma construção individual e completamente dissociada do biológico ou psicológico.

Há, em geral, um desconforto em relação ao sexo anatômico, que gera a busca por tratamentos hormonais e cirúrgicos para a tão almejada adequação (LIONÇO, 2009, p. 53/54). Ressalta-se, por outro lado, que não necessariamente a cirurgia será imprescindível.

É que a pessoa transexual pode suprir a necessidade de modificação do sexo realizando ou não a cirurgia de redesignação sexual, sendo esta prescindível quando lembramos que a identidade de gênero não é verificada a partir de uma ótica essencializadora de acordo com o aparelho genital dos indivíduos.

A cultura identitária transexual (identidade trans) traz em seu bojo a discussão do gênero dentro da diversidade sexual, a ser entendido como uma construção, também cultural, ligada à história pessoal de cada indivíduo. Não é pré-discursivo e enseja interpretação ampla e não estática.

Butler (2004, p. 08), tratando sobre o gênero, questiona os casos em que não se pode enquadrar o gênero dentro do que se entende por masculino ou feminino, pois nem sempre descreverá tais orientações. E ainda, as identidades masculinas e femininas na verdade são 
originárias e descritas sob a perspectiva da experiência de outra pessoa e não necessariamente do próprio indivíduo, que acaba por aceita-las para fins de adequação em sociedade.

Bento \& Pelúcio (2012), em pesquisa realizada, trabalham com uma sexualidade fundada em dois sexos opostos erguidos sobre a base de uma bipolaridade, o que vem a corroborar a construção social com base em um pensamento hétero que pretende excluir toda a forma de identidade que seja dele dissociado.

No momento em que o sexo biológico (aqui entendimento apenas como os aparelhos sexuais) não condiz com a identidade de gênero, ocorre o que se chama pressão essencializadora, que pretende reduzir a condição considerada natural homem/mulher e reputa tudo que se opõe a essa condição como abjeção e ignomínia. Aponta-se como prática comum nesses casos o abandono do nome registral como forma de ignorá-lo em termos de gênero (NETO \& AGNOLETI, 2008, p. 61).

Bento (2003) aponta a problemática da desconsideração do gênero em detrimento de situações puramente biológicas da natureza:

O gênero adquire vida através das roupas que cobrem o corpo, dos gestos, dos olhares, de uma estilística corporal e estética definida como apropriada. São estes sinais exteriores, postos em ação, que estabilizam e dão visibilidade ao corpo, que é basicamente instável, flexível e plástico. Essas infindáveis repetições funcionam como citações e cada ato é uma citação daquelas verdades estabelecidas para os gêneros, tendo como fundamento para sua existência a crença de que são determinados pela natureza.

A análise das identidades de gênero sob o ponto de vista binário não condiz com as teorias mais atuais sobre a temática. A identidade será formulada no modo como o indivíduo se relaciona no universo sociocultural, não se tratando de uma experiência única, distinta para cada um. A Teoria Queer questiona a identidade como substância e propõe pensarmos o quanto os corpos são modificados pelas imposições culturais, que também vincula padrões estéticos, morais e até mesmo higiênicos de acordo com cada grupo (GALLI et al, 2013, p. 449).

No mesmo sentido, o corpo torna-se o lugar para a construção social, de acordo com os processos discursivos vigentes na cultura e que transformam os atributos corporais e definidores do gênero e do sujeito (GALLI et al, 2013, p. 454).

A vivência da identidade de gênero, destarte, não está limitada ao sexo registral, ao aparelho sexual ou à uma única forma de vida. O conceito é novo e demonstra coerência principalmente quando contrastado com a forte influência heteronormativa em sociedade, que 
ainda encontra-se arraigada em campos diversos e influencia comportamentos sem que as pessoas se deem conta disso.

A identidade trans, então, está associada à vivência individual do gênero, desvinculado de paradigmas estáticos, previamente indutivos e muito menos psíquicos. Não existe identidade transexual universal, pois esta é compreendida como mais uma possibilidade humana de determinação do gênero, bem como uma direção de relativa autonomia (trans-autonomia) em relação às definições hegemônicas (GALLI et al, 2013, p. 456).

Alves \& Moreira (2015, p. 62) lembram que o gênero é tomado como forma de discurso provisório, posto que em constante constituição. É confrontado com o binarismo social, político e ideológico.

Por outro lado, esta vertente da cultura identitária LGBT é uma das que mais encontra repulsa em sua representação em sociedade, na medida em que os conceitos identitários e suas complexas nuances não são bem compreendidos e acabam de servir como base para práticas de preconceito que violam os direitos constitucionais dos cidadãos e cidadãs transexuais. Esta repulsa, inclusive, tem se mostrado mais forte do que os próprios princípios da República (BENTO\&PELÚCIO, 2012).

No mesmo sentido:

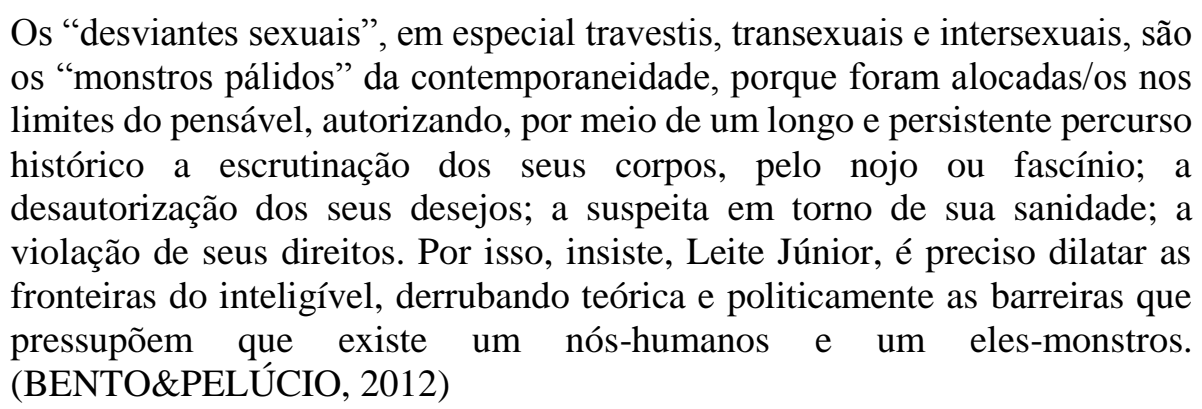

Não são necessárias grandes digressões para inferir que o repúdio tão fortemente difundido pela sociedade conservadora, perpetrado em diversas formas de preconceito, é causa determinante para a exclusão social da população transexual.

Por esta razão, todos os representantes da identidade trans vêm buscando formas de implementação de seus direitos, tais como o nome social e uso do banheiro feminino, para que possam efetivamente conviver em sociedade sem que seja necessário viver escondidos, pois tal atitude, além da exclusão social, gera problemas relacionados à saúde, educação, mercado de trabalho, dentre outros. A sociedade não pode ignorar variadas formas populacionais e 
identitárias, sob pena de verdadeira crise de Estado, pois a empírica demonstra as consequências da exclusão aqui mencionada.

O exercício da democracia está umbilicalmente ligado à consideração de todas as formas de existência em um país, livres de preconceitos, ao passo que garantir o bem de todos independentemente de estigmas é objetivo fundamental da República Federativa do Brasil (CONSTITUIÇÃO FEDERAL. Artigo 3, inciso IV).

Neste aspecto, a discussão sobre variadas formas identitárias são imprescindíveis para, cada vez mais, inseri-las efetivamente em sociedade, concedendo-lhes voz para as reivindicações e para o auxílio à formação de uma identidade por fim isenta de preconceitos e plural em sentido igualitário, sem descaracterização das diferenças, e por meio da qual seja possível expressar-se e, ainda assim, sentir-se parte do todo social coletivo.

Nos dias atuais, a vertente LGBT ligada à transexualidade luta então para desvincular a sua vivência trans ao condicionamento cirúrgico (CONSELHO FEDERAL DE MEDICINA. Resolução n. 1.955 de 3 de setembro de 2010), o qual, para ser realizado pelos meios públicos determina, por sua vez, o condicionamento ao diagnóstico.

$\mathrm{O}$ ordenamento jurídico brasileiro, pela lei civilista, prescreve que à pessoa não é deferido dispor de seu corpo (BRASIL. Código Civil. Lei 10.406 de 10 de janeiro de 2002, artigo 13). Assim, não havendo lei que determine a realização da cirurgia de modificação do sexo, não se pode admitir que o Estado o faça, quando o ato cirúrgico não é a medida correta para a constatação da identidade de gênero por meio da conformação corporal. Ademais, o enunciado 6 da $1^{\text {a }}$ Jornada do Centro de Estudos da Justiça Federal ${ }^{3}$ aponta que a exigência contida no artigo 13 refere-se ao bem-estar físico e psíquico.

Por outro lado, não se podem olvidar os casos em que o indivíduo efetivamente pretende realizar a cirurgia de transgenitalização e recorre ao Sistema Único de Saúde - SUS para tal. Lá, após ser submetido à junta que o avaliará, passa a ser diagnosticado em transexualismo e disforia de gênero e, somente a partir de então, é possível dedicar-lhe atenção integral à sua saúde para o processo de transgenitalização. Logo, o diagnóstico estaria associado a um tratamento à transexualidade, o que fere série de direitos inerentes à sua personalidade.

\footnotetext{
${ }^{3}$ Enunciado 6 - Art. 13: A expressão "exigência médica" contida no art. 13 refere-se tanto ao bem-estar físico quanto ao bem-estar psíquico do disponente.
}

Rev. de Gênero, Sexualidade e Direito | e-ISSN: 2525-9849 | Brasília | v. 3 | n. 1 | p. 108 - 123 | Jan/Jun. 2017 


\section{PATOLOGIZAÇÃO: MAL (DES)NECESSÁRIO}

Malgrado o diagnóstico garanta o atendimento gratuito pelo SUS, o preço que se paga por isso tem sido alto demais, quando a medida correta seria atenção integral à saúde independentemente de patologização da transexualidade. Trata-se de uma problemática que a identidade trans, ainda nos dias atuais, seja considerada patologia (BUTLER, 2009, p. 96).

Dentro da discussão das questões de gênero, quando consideramos que as identidades estão associadas à vivência e intimidade e não ao aparelho sexual, não se abre espaço para considerar que dita associação esteja ligada a transtorno mental. De outro lado, é por meio deste "transtorno" que a população transexual tem logrado atendimento gratuito que a aproxima da modificação de seu corpo quando assim deseja fazê-lo.

Entretanto, dita submissão ao diagnóstico fomenta atos de poder da transfobia ${ }^{4}$ que utilizará a patologia para deslegitimar o movimento e a inserção da população trans em sociedade, pois exige-se que, para tanto, estejam de acordo com o que a sociedade heteronormativa, isto é, aquela que se guia por padrões de comportamento heterossexual, permita e entenda adequado. Muitas vezes a questão sequer está ligada ao desejo de modificar o corpo, mas a vontade efetiva de pertencer à sociedade dominadora.

Ocorre que a premissa de inclusão social é equivocada. Butler (2003), muito bem lembra que a patologia da transexualidade pode acarretar ação mas, sobretudo, pode também acarretar em restrições, as quais, inevitavelmente, culminam em exclusão social. Por esta razão, a discussão que se desponta é aquela sobre o fim da patologização e oferecimento de tratamento à população transexual independentemente de um diagnóstico, apenas de acordo com a sua autonomia em modificar seu corpo quando quiser.

Durante reunião realizada pelo Comitê Técnico de Saúde da População LGBT, discutiu-se o assunto, na forma a seguir trazida por Lionço (2009):

A reunião sobre o processo transexualizador no SUS, portanto, enfatizou a necessária despatologização da transexualidade como estratégia de promoção da saúde, e afirmou a pluralidade na transexualidade, considerando que a autonomia da pessoa transexual na tomada de decisão sobre as medidas necessárias a uma melhor qualidade de vida seria fundamental para que a atenção à saúde não dispusesse novos mecanismos de controle e normatização sobre as condutas e modos de vida e de subjetivação. As cirurgias, portanto, passaram a ser compreendidas como parte ou não do Processo

\footnotetext{
${ }^{4}$ Sentimento de aversão e ojeriza à pessoa transexual.
} 
Transexualizador, e a discussão superou o viés medicalizador e correcional para o foco na garantia do direito à saúde integral.

É certo que a saúde é direito de todos, cujo atendimento deve ser universalizado (CONSTITUIÇÃO FEDERAL. 1988, artigo 196) e, baseado nessa premissa, não é razoável patologizar uma vivência para, somente então, garantir à pessoa transexual que, antes de mais nada, é ser humano portador de dignidade, tratamento pretendido no âmbito de sua vida privada, que, igualmente, é inviolável (CONSTITUIÇÃO FEDERAL. 1988, artigo 5, inciso X).

A identidade de gênero é uma construção individual formada a partir de diversos fatores, todos de matriz cultural em sentido amplo. Inclusive, muito se questiona a capacitação científico e acadêmica para inserir a transexualidade como patologia associada a transtorno mental. Bento \& Pelúcio (2012) trazem clara reflexão sobre o tema:

Por fim, chegamos ao verdadeiro conteúdo do DSM-IV: é um texto que materializa uma visão cultural hegemônica e singular de gênero, mas que, contraditoriamente, consegue seu êxito por apresentar-se como universal porque tem como aliada a retórica da cientificidade de seus achados. Portanto, a defesa da diferença sexual como dado primeiro para se definir o gênero é uma construção de gênero. É preciso reafirmar que o DSM-IV, o CID-10 e o SOC são falaciosos e produtores institucionais de identidades abjetas. Quem formula esses códigos é um grupo fechado de especialistas orientados pelos preceitos heteronormativos que, aliás, têm fundamentado a ciência ocidental moderna.

A campanha internacional Stop Trans Pathologization (Parem a Patologização Trans), a ser seguida e implementada pelos países, aporta pontos de ação e, sobre o caso, orienta aos Estados a:

Ação 4: Reconhecer legalmente a identidade de gênero de pessoas trans em documentos oficiais por meio de processos administrativos simples e fundamentados na autoidentificação, sem requisitos abusivos como diagnóstico médico forçado, esterilização, tratamento médico ou divórcio.

[...]

Ação 7: Reformar as classificações médicas nacionais e internacionais que tratam ser trans como uma doença (NAÇÕES UNIDAS, Campanha Livres e Iguais, Pontos de Ação).

Desta maneira, em tempos de tão franca intolerância, tem-se verdadeiro retrocesso quando se fala em transexualismo e disforia de gênero, termos ligados a transtornos psíquicos, para tratar da transexualidade, a qual deve ser considerada pura e simplesmente como mais uma forma de manifestação identitária e, como tal, respeitada em todas as esferas sociais, inclusive 
quando da obtenção de tratamento junto ao Sistema Único de Saúde, que não pode condicionálo a um laudo médico psiquiátrico.

\section{DIGNIDADE DA PESSOA HUMANA FRENTE AO DIAGNÓSTICO}

A Constituição Federal está fundamentada no princípio da dignidade da pessoa humana (CONSTITUIÇÃO FEDERAL. 1988, artigo $1^{\circ}$, III), garantida a todo cidadão em suas relações sociais, inclusive nesta aqui discutida, já que não é digno, sob o ponto de vista físico e moral, que o transexual, cuja sexualidade deve ser designada pelo gênero, seja compelido a submeter-se ao diagnóstico para ter acesso ao Sistema Único de Saúde - SUS, como pessoa trans, em respeito ao seu gênero. De fato, o sexo designativo do ser humano é aquele associado à sua identidade de gênero e todas as suas tão complexas, e pessoais, nuances.

A identidade de gênero, formação cultural pessoal de cada qual, não é patologia. Assim, ater-se ao diagnóstico para somente então conceder à pessoa transexual atenção integral à saúde fere frontalmente sua dignidade e não parece ser o melhor caminho social e humano. A pessoa trans pode associar o gênero masculino ou feminino e mesmo assim não pretender realizar cirurgia de alteração de sexo, mas sempre necessitará do acesso a todos os tratamentos de saúde de acordo com seu gênero. Logo, a cirurgia é opção e não finalmente a cura para sua vivência que não é diagnóstico.

Segundo o pensamento oficial todos/as transexuais desejam como solução para seus conflitos a realização das cirurgias de transgenitação. Este cânone, no entanto, tem sido questionado por muitos/as transexuais que reivindicam suas identidades de gênero legal sem se submeterem à cirurgia. [...] Este sentimento de ser incompleto ou estar em débito nos persegue porque o fundamento que se supõe determinante das identidades e demiurgo dos desejos, o corpo, é o resultado de próteses discursos. (BENTO, 2012)

Para Silveira e Campello (2010), a dignidade humana é concretizada por um valor preponderante em um dado momento histórico, tal como a liberdade, igualdade, entre outros. Lembram também que a dignidade é fundamento dos direitos humanos.

Sarlet (2015, p. 55) também ressalta que a dignidade não possui apenas valor ontológico, mas cultural, construído de gerações em gerações e da humanidade em seu todo, abarcando então um conceito natural e cultural. 
A esse passo, inserindo a comunidade LGBT no atual cenário histórico de reivindicações por espaço em sociedade, para que estes indivíduos sejam considerados efetivamente cidadãos, a identidade trans deve ser reconhecida para a garantia de sua participação na condição de sujeito de direitos e como forma de substancializar o postulado da dignidade para que não seja apenas um princípio vago.

Nunes (2008, p. 51) lembra que em um dado momento o indivíduo necessita, em meio ao seu desenvolvimento, ter respeitadas suas ações e seu comportamento, ou seja, sua liberdade, imagem, intimidade e tudo mais que componha sua dignidade. Para tanto, é necessário desvincular o padrão heterossexual e abrir margem a todas as formas de diversidade dentro de uma regulamentação geral.

Em sede internacional, no ano de 2006, reuniram-se em Yogyakarta, na Indonésia, especialistas em orientação sexual e gênero, dispondo na ocasião que este é estabelecido de acordo com a autonomia de cada um, experiência interna e individual, aliada ao sexo de nascimento ou outros meios de viver e sentir.

Lavraram-se então os Princípios de Yogyakarta ${ }^{5}$, que trazem diretrizes para o respeito aos direitos humanos daqueles que exerçam seu gênero, lastreados em argumentos firmes da autodeterminação, liberdade, privacidade e especialmente a dignidade.

Interpretando a Declaração Universal de Direitos Humanos, a OEA - Organização dos Estados Americanos editou a Resolução 2435/08 (OEA. 2008) associa o gênero e orientação sexual o direito de liberdade, à vida e à segurança.

A Convenção Americana de Direitos Humanos, recepcionada no ordenamento brasileiro (BRASIL. Decreto 678, 1992), igualmente estabelece normas de proibição de preconceito de qualquer condição e preservação da integridade física ( $\operatorname{artigos} 1^{\circ}$ e $5^{\circ}$ ), as quais são normas que estabelecem preceitos fundamentais.

\footnotetext{
${ }^{5}$ Princípio 3. Direito ao Reconhecimento Perante à Lei: Toda pessoa tem o direito de ser reconhecida, em qualquer lugar, como pessoa perante a lei. As pessoas de orientações sexuais e identidades de gênero diversas devem gozar de capacidade jurídica em todos os aspectos da vida. A orientação sexual e identidade de gênero auto definidas por cada pessoa constituem parte essencial de sua personalidade e um dos aspectos mais básicos de sua autodeterminação, dignidade e liberdade. Nenhuma pessoa deverá ser forçada a se submeter a procedimentos médicos, inclusive cirurgia de mudança de sexo, esterilização ou terapia hormonal, como requisito para o reconhecimento legal de sua identidade de gênero. Nenhum status, como casamento ou status parental, pode ser invocado para evitar o reconhecimento legal da identidade de gênero de uma pessoa. Nenhuma pessoa deve ser submetida a pressões para esconder, reprimir ou negar sua orientação sexual ou identidade de gênero.

Princípio 6. Direito à Privacidade: Toda pessoa, independente de sua orientação sexual ou identidade de gênero, tem o direito de desfrutar de privacidade, sem interferência arbitrária ou ilegal, inclusive em relação à sua família, residência e correspondência, assim como o direito à proteção contra ataques ilegais à sua honra e reputação. $\mathrm{O}$ direito à privacidade normalmente inclui a opção de revelar ou não informações relativas à sua orientação sexual ou identidade de gênero, assim como decisões e escolhas relativas a seu próprio corpo e a relações sexuais consensuais e outras relações pessoais.
} 
Outrossim, atualmente há orientação do Conselho Nacional de Justiça ${ }^{6}$ para que não seja exigida cirurgia quando demonstrado o sentimento de identidade sentida diferente daquela biológica. Vê-se que em momento algum os dispositivos mencionados tratam da questão da identidade de gênero como patologia, eis que a leitura está muito mais associada à questão humanitária em respeito à intimidade do indivíduo (CONSTITUIÇÃO FEDERAL. Artigo 5, $\mathrm{X}$ ) do que da ingerência médica tão questionável e tão prejudicial ao caso em comento.

\section{POLÍTICAS PÚBLICAS NECESSÁRIAS}

Existem benefícios para as pessoas transexuais diagnosticadas psiquicamente quel logram atendimento e assistência médica para a realização do tratamento de redesignação sexual? Mas a que preço?

Tratando em caso concreto da experiência de atenção à saúde para pessoa transexual, Sampaio \& Coelho (2012), trazem o seguinte depoimento:

No que diz respeito às relações sociais, Paulo relata o desagrado em saber que, para poder fazer as cirurgias e ter um alívio quanto ao seu desconforto, terá de ser considerado como um "transtornado; isso é desrespeitoso. Você pode não ser considerado louco, mas você está com um laudo de um transtorno mental e isso é ruim".

A Constituição Federal está fundada no princípio da dignidade da pessoa humana e objetiva o bem de todos sem quaisquer formas de discriminação (CONSTITUIÇÃO FEDERAL. 1988, artigo 1, inciso III e artigo 3, inciso IV). Nesse aspecto, é certo que estes direitos não vêm sendo respeitados com a patologização da transexualidade, haja vista que o condicionamento do laudo psiquiátrico vem juntamente com uma gama de preconceitos que, cedo ou tarde, serão utilizados justamente para hostilizar e excluir.

Esta é a razão pela qual o caminho já percorrido, que nos trouxe até aqui e subsidiou o atendimento gratuito, deve ser deixado para trás para dar lugar às novas discussões sobre a identidade de gênero, estas sim adequadas à atualidade e que certamente são inclusivas e não pretendem enquadrar esta ou aquela parcela social em um código ou manual de doenças psiquiátricas, mas apresentá-las a possibilidade de ser quem realmente são e poder afirmar-se

\footnotetext{
${ }^{6}$ Enunciado no ${ }^{\mathbf{0}}$ 42: Quando comprovado o desejo de viver e ser aceito enquanto pessoa do sexo oposto, resultando numa incongruência entre a identidade determinada pela anatomia de nascimento e a identidade sentida, a cirurgia de transgenitalização é dispensável para a retificação de nome no registro civil.

Enunciado no ${ }^{\circ}$ 43: É possível a retificação do sexo jurídico sem a realização da cirurgia de transgenitalização.
} 
como tal em sociedade, garantindo seu acesso a todos os bens sociais necessários ao que se chama exercício da cidadania.

A ênfase na autonomia da pessoa transexual na tomada de decisão sobre as estratégias médico-cirúrgicas necessárias à melhoria da qualidade de vida é uma diretriz fundamental para que a atenção à saúde de transexuais não se restrinja a novos mecanismos de poder e controle sobre os corpos e condutas sexuais das pessoas. Da mesma forma, a ênfase no processo de superação dos agravos decorrentes dos processos discriminatórios, sustentado na diretriz da atuação multiprofissional e do cuidado sobre os laços sociais e da inserção social, é um ganho fundamental dessa norma técnica proposta pelo Ministério da Saúde. (LIONÇO, 2009)

Alves \& Moreira (2015, p. 62) lembram que o gênero é tomado como forma de discurso provisório, posto que em constante constituição. É confrontado com o binarismo social, político e ideológico.

O direito possui papel fundamental na efetivação da autonomia e dignidade da população transexual, pois seu caráter dinâmico acompanha as mudanças sociais e, consequentemente, garante a aplicação da justiça igualitária, para que o preconceito não seja fomentado por práticas inseridas para legitimar o poder heteronormativo e exigir padrão de comportamento em sociedade que nunca foi e nunca será igual e, como tal, deve ter seu multiculturalismo respeitado.

Em recentíssima decisão, o Superior Tribunal de Justiça (2017) entendeu que a pessoa transexual pode alterar o sexo em seu registro sem que, para isso, realize a cirurgia de modificação sexual. Este precedente em muito beneficia a comunidade trans e serve também como embasamento para a desnecessidade do enquadramento da transexualidade como patologia, já que devem ser levados, sobretudo, em consideração seu direito à dignidade e felicidade na proteção de sua personalidade (SUPERIOR TRIBUNAL DE JUSTIÇA. Recurso Especial n. 1626739/RS).

Por outro lado, sabe-se que o judiciário não pode servir à criação de políticas públicas e que também não abarcará todos os casos a serem protegidos. Portanto, a vertente que se espera é justamente a modificação do olhar para a criação de Políticas Públicas de acesso integral à sociedade pelas pessoas transexuais e garantias de seus direitos de personalidade, protegidos pela Constituição Federal. 


\section{CONCLUSÕES}

Pretendeu-se, com a presente pesquisa, acender a chama sobre a necessidade de reflexão sobre o problema da patologização da transexualidade e todas as vertentes acarretadas por ela, as quais, inevitavelmente, levam não só à exclusão social, mas também acarretam à população trans a falta de cuidados básicos com sua saúde, já que, caso queiram ser aceitos por sua identidade de gênero, devem submeter-se ao diagnóstico.

De outro lado, o gênero não está associado à doença, mas à construção da personalidade de cada um, que abarca sua história e sua cultura. É de fato a expressão máxima da intimidade de qualquer um, que, neste caso específico, tem servido como forma de marginalização, disseminação de preconceito e ingerência estatal.

A esse passo, é necessária leitura do tema a luz do ordenamento jurídico, este imprescindível para barrar pretensões de cunho preconceituoso e cujo embasamento científico tanto se questiona. A dignidade deve falar mais alto quando o assunto está umbilicalmente atrelado a questões humanas.

Em termos de breves resultados, pôde-se constar a necessidade da despatologização, a qual já vem sendo discutida e buscada pelos segmentos sociais e, principalmente, conscientização da população, mormente da LGBT, desta problemática, já que, mesmo que inicialmente haja benefício por trás do tratamento decorrente do laudo médico psiquiátrico, o preço a ser pago vem posteriormente e de forma muito mais grave. Portanto, o mal tratado no título do trabalho é realmente um mal desnecessário quando há interesses muito maiores em questão. A hipótese inicial confirma-se neste aspecto.

De outro lado, apesar de imprescindível na tentativa de amenização das mazelas sociais, o direito não pode sozinho assumir compromisso que é estatal. Fazem-se necessárias mais Políticas Públicas sobre a temática, a maior difusão da necessidade de acabar com a patologização de pessoas que apenas pretendem viver sua vida e identidade de maneira plena, fazendo valer a Campanha Stop Trans Pathologization.

O estado da arte demonstra necessidade de aprofundamento na pesquisa, inclusive por meio da empírica para a constatação do sentimento de exclusão gerado tanto pela patologização quanto pelos efeitos posteriores em termos de desvalorização da população transexual, mormente quando a cirurgia de transgenitalização é realizada em razão da submissão ao diagnóstico. 
A heteronormatividade encontra-se inserida nas mais diversas nuances sociais, tal como aqui demonstrado. Uma vez rendidos às exigências de condutas heterossexuais, a população LGBT a elas estará atrelada e mais difícil será sua emancipação. Por essa razão, a luta pela igualdade deve ocorrer antes da patologia e não depois. O direito, associado ao Estado entendido em ternos de gestão pública, tal como exposto, possuem papel providencial nesta empreitada pela plena inclusão social.

\section{REFERÊNCIAS}

ALVES, Cláudio Eduardo Resende; MOREIRA, Maria Ignez Costa. Do uso do nome social ao uso do banheiro: (trans) subjetividades em escolas brasileiras. Quaderns de Psicologia 2015, Vol. 17, No 3, 59-69. Disponível em:

<http://www.raco.cat/index.php/QuadernsPsicologia/article/viewFile/303189/392825>.

Acesso em 20 out. 2016.

BRASIL. Constituição. Brasília: Senado Federal, 1988. Disponível em:

<http://www.planalto.gov.br/ ccivil_03/Constituicao/Constituiçao.htm>. Acesso em: 24 jun.

2016.

Casa Civil. Lei 10.406 de 10 de janeiro de 2002. Código Civil. 1988. Disponível em: <http://www.planalto.gov.br/ccivil_03/leis/2002/110406.htm>. Acesso em 25 mai, 2016.

Casa Civil. Decreto nº 678 de 06 de novembro de 1992. Promulga a Convenção Americana sobre Direitos Humanos (Pacto de São José da Costa Rica), de 22 de novembro de 1969. Disponível em:< http://www.planalto.gov.br/ccivil_03/decreto/D0678.htm>. Acesso em: 20 jun. 2015.

Superior Tribunal de Justiça. Provimento do Recurso Especial. Recurso Especial n. 1626739, de 09 de maio de 2017. Julgamento pela Quarta Turma. Relator Ministro Luis Felipe Salomão. Disponível em: < https://ww2.stj.jus.br/processo/revista/inteiroteor/?num_registro=201602455869\&dt_publicac ao=01/08/2017>. Acesso em 15 de ago. 2017.

BENTO, Berenice. Transexuais, corpos e próteses. In: Revista de Estudos Feministas. Vol.20 no.4 Florianópolis ago/dez. 2003. Disponível em:< https://gedsfdusp.files.wordpress.com/2015/08/06-bento-berenice-transexuais-corpos-eprc3b3teses.pdf $>$. Acesso em 10 out. 2016.

; PELÚCIO, Larissa. Vivências trans - desafios, dissidências e conformações apresentação. In: Revista de Estudos Feministas. Vol.20 no.2 Florianópolis May/Aug. 2012. Disponível em: <http://www.scielo.br/scielo.php?script=sci_arttext\&pid=S0104026X2012000200009>. Acesso em 13 out. 2016.

; PELÚCIO, Larissa. Despatologização do gênero: a politização das identidades abjetas. In: Revista de Estudos Feministas. vol.20 no.2 Florianópolis May/Aug. 2012. 
Disponível em: < http://www.scielo.br/scielo.php?script=sci_arttext\&pid=S0104026X2012000200017 >. Acesso em 15 mai. 2017.

BUTLER, Judith. El género em disputa: El feminismo y la subversión de la identidade. Espanha: Editorial de Espasa Libros, S.L.U, 2004.

. Desdiagnosticando o Gênero. Physis Revista de Saúde Coletiva, Rio de Janeiro, 19 [ 1 ]: 95-126, 2009. Disponível em: <http://www.scielo.br/pdf/physis/v19n1/v19n1a06.pdf>. Acesso em 10 mai. 2016.

CAMPELLO, Lívia Gaigher Bósio; DA SILVEIRA, Vladimir Oliveira. Dignidade, Cidadania e Direitos Humanos. Trabalho publicado nos Anais do XIX Encontro Nacional do CONPEDI realizado em Fortaleza - CE nos dias 09, 10, 11 e 12 de Junho de 2010. Disponível em:

<htttp://www.publicadireito.com.br/conpedi/manaus/arquivos/anais/fortaleza/3914.pdf >. Acesso em 05 set. 2016.

CONSELHO FEDERAL DE MEDICINA. Resolução n. 1.955 de 3 de setembro de 2010. Dispõe sobre a cirurgia de transgenitalismo e revoga a Resolução CFM n ${ }^{\circ}$ 1.652/02. Disponível em: < http://www.portalmedico.org.br/resolucoes/CFM/2010/1955_2010.htm>. Acesso em 15 nov. 2016.

CONSELHO NACIONAL DE JUSTIÇA. Enunciados. Disponível em:< http://www.cnj.jus.br/>. Acesso em: 10 jun. 2015.

CONSELHO DA JUSTIÇA FEDERAL. Enunciados. Disponível em:< http://www.cjf.jus.br/cjf/CEJ-Coedi/jornadas-cej/enunciados-aprovados-da-i-iii-iv-e-vjornada-de-direito-civil/compilacaoenunciadosaprovados1-3-4jornadadircivilnum.pdf/view>. Acesso: 25 mai. 2016.

GALLI, Rafael Alves; VIEIRA, Elizabeth Meloni. GIAMI, Alain; DOS SANTOS, Manoel Antônio. Corpos Mutantes, Mulheres Intrigantes: Transexualidade e Cirurgia de Redesignação Sexual. Revista Psicologia: Teoria e Pesquisa Out-Dez2013. Vol. 29 n.4, pp.447-457. Disponível em: < http://www.scielo.br/pdf/ptp/v29n4/v29n4a11.pdf>. Acesso em 07 de nov. 2016.

LIONÇO, Tatiane. Atenção integral à saúde e diversidade sexual no Processo Transexualizador do SUS: avanços, impasses, desafios. Revista Physis vol. 19 no. 1 Rio de Janeiro 2009. Disponível em: < http://www.scielo.br/pdf/physis/v19n1/v19n1a04.pdf>. Acesso em 09 nov. 2016.

MELLO NETO, José Baptista; AGNOLETI, Micheli B. Dignidade Sexual e Diversidade Humana: cidadania e respeito para lésbicas, gays, bissexuais, travestis e transexuais (LGBTT) In: ZENAIDE, Maria de Nazaré Tavares, et al. DIREITOS HUMANOS: capacitação de educadores Vol. II; João Pessoa: Universitária/UFPB, 2008.

NUNES, Rizzatto. O Princípio Constitucional da Dignidade da Pessoa Humana. 2. ed.São Paulo: Editora Saraiva, 2008. 
ORGANIZAÇÃO MUNDIAL DA SAÚDE. Classificação Estatística Internacional de Doenças e Problemas relacionados à Saúde. Décima Revisão CID 10. Disponível em<http://www.datasus.gov.br/cid10/webhelp/cid10.htm>. Acesso em 09 nov. 2016.

ORGANIZAÇÃO DOS ESTADOS AMERICANOS. Resolução 2435 de 3 de junho de 2008. Direitos Humanos, Orientação Sexual e Identidade de Gênero. Disponível em:< http://portais.ufg.br/up/16/o/pplgbt-180.pdf >. Acesso em 20 de mai. 2016.

PRINCÍPIOS DE YOGYAKARTA. Disponível em:< http://www.dhnet.org.br/direitos/sos/gays/principios_de_yogyakarta.pdf $>$. Acesso em 19 mai. 2016.

SAMPAIO, Liliana Lopes Pedral; COELHO, Maria Thereza Ávila Dantas. Transexualidade: aspectos psicológicos e novas demandas ao setor de saúde. Revista Interface Comunicação Saúde Educação, vol. 16 no. 42, p. 637-49, jul/set. 2012. Disponível em:< http://www.scielo.br/scielo.php?script=sci_arttext\&pid=S1414-32832012000300005>.

Acesso em 08 out. 2016.

SARLET, Ingo Wolfgang. Dignidade (da Pessoa) Humana e Direitos Fundamentais na Constituição Federal de 1988. 10. ed.Porto Alegre: Livraria do Advogado, 2015.

STOP TRANS PATHOLOGIZATION. Rede Internacional pela Despatologização Trans, 2012. Disponível em:< http://stp2012.info/old/pt/manifesto>. Acesso em 20 set. 2017. 